\section{Saisonale affektive Störung}

Helga Peter

Marburg, Deutschland

\section{Synonyme}

SAD; Winterdepression

\section{Englischer Begriff}

seasonal affective disorder

\section{Definition}

Eine saisonal induzierte $\triangleright$,Affektive Störung“, die meist im Herbst oder Spätherbst auftritt, wenn in den nördlichen Breitengraden die Tage kürzer werden. Es wird vermutet, dass die mit der Herbstzeit verbundene Abnahme des Tageslichtes mitverantwortlich für die depressive Verstimmung ist. Die Betroffenen sind während der eher durch Helligkeit geprägten Jahreszeiten typischerweise beschwerdefrei, die Depressivität tritt aber regelhaft jährlich im Herbst auf und hält unbehandelt mehrere Monate lang an. Therapeutisch wird eine $>$,Lichttherapie" mit mehr als 2000 Lux über eine Zeitspanne von mehr als zwei Stunden, am besten morgens von 6-8 Uhr über den Zeitraum von Oktober bis Februar empfohlen.

Siehe auch $>$,Chronobiologie“. 